\title{
Outbreak of Paratyphoid in the Edinburgh Area
}

\author{
J. C. M. SHARP,* M.B., CH.B., D.P.H. ; P. P. BROWN, † M.B., B.S., DIP.BACT. ; G. SANGSTER, $\ddagger$ M.D.
}

Brit. med. F., 1964, 1, 1282-1285

From time to time outbreaks of paratyphoid infection have occurred in the United Kingdom, most of which in recent years have been attributable to imported food ingredients, especially frozen Chinese egg and desiccated coconut. Of the many phage types of Salmonella paratyphi $B$, the Taunton strain has been prominent, notably in Eastbourne, Southwark, Motherwell, and the Manchester area (Cockburn et al., 1951 ; Cameron, 1959 ; Young, 1960 ; Anderson, 1962). More recently similar outbreaks have occurred in East Anglia, Surrey, and Yorkshire (Brit. med. F., 1963).

In the early months of 1963 an extensive outbreak of paratyphoid B fever occurred in the Edinburgh area, caused primarily by infected bakery confectionery. The organism responsible was Salm. paratyphi $B$, phage type Taunton. At least 188 persons were infected between late December 1962 and May 1963, of whom 165 belonged to the city and 23 were resident in the neighbouring counties of Midlothian (17), West Lothian (4), East Lothian (1), and Berwickshire (1). This is the largest outbreak of paratyphoid in Scotland since 1940, when 274 cases were reported in Glasgow (Macgregor, 1940). Since the initial outbreak a further seven cases of paratyphoid fever have occurred sporadically during the year; four in Edinburgh and three in areas adjoining the city. Salm. paratyphi $B$, phage type Taunton, was also isolated from six other cases that appeared in the Border counties in April and May, none of which could be linked with the Edinburgh outbreak.

\section{The Outbreak}

On 8 January 1963 paratyphoid fever was diagnosed in a girl aged 9 years who had been admitted to the infectious diseases unit of the Edinburgh City Hospital. The second case on 10 January from outside the city had developed " puerperal pyrexia" in an Edinburgh maternity unit. Next day two further cases were diagnosed in the same hospital. One of these patients had been operated on for appendicitis, but the appendix was found to be normal and she continued to be febrile postoperatively. The other was a staff nurse from another ward. These three adult cases were diagnosed almost simultaneously by blood-cultures on investigation of pyrexia of unknown origin in separate wards of this hospital.

Routine inquiries revealed that the first patient had attended several children's Christmas parties, any of which could have been the source of infection, but no apparent connexion was established at this stage between the child and the adult cases. While these inquiries were proceeding, on 14 January information was received from the father of the first patient that while visiting hospital he had met the parents of two other children who had also been admitted for investigation. All three children had been at the same party on 23 December, which had not been mentioned hitherto in the list of parties attended.

The organizers of this party supplied details of the menu, the caterers involved, and a list of 155 child guests. These children were all visited and arrangements made for stools to

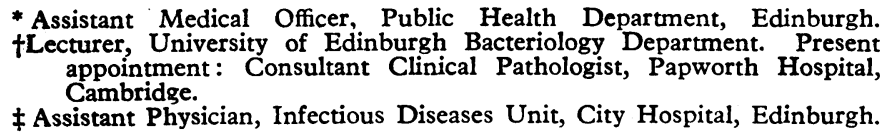

be bacteriologically examined. Where there was any illness the family doctor was immediately informed by telephone of the possibility of paratyphoid fever. These investigations revealed infection in 16 children, including seven symptomless excreters. Meanwhile four other party children had been admitted to hospital. As all 23 children had eaten individual cream trifles at the party, which appeared to be the most likely vehicle of infection, the bakery concerned (bakery $\mathrm{X}$ ) was visited. The trifles of sponge-cake, jam, and custard, with artificial cream on top, were made on Saturday, 22 December (probably the baker's busiest day in the year) and were delivered to the party premises the same day. They lay overnight in an unheated room until consumed the following afternoon. During this week-end alone the bakery had made and distributed several thousand artificial-cream products, including 800 trifles.

No food from the party remained for examination, but bacteriological examination of artificial and natural cream in the bakery was carried out immediately and continued at regular intervals thereafter. Chinese frozen whole egg, egg albumen, desiccated coconut, and a wide range of other raw products were sampled and examined, together with equipment used in the bakehouse. Moore's (1948) swabs were placed in the drains. All these gave negative results. As bakery $X$ uses 5 tons $(5,080 \mathrm{~kg}$.) of Chinese egg monthly, it was not expected that any of the batch in use at the relevant time would be available for examination. However, 30 samples of the same consignment found in a cold store were also negative. It was later learned from the Food Hygiene Laboratory, Colindale, that Salm. paratyphi B, phage type Taunton, had been isolated from one tin of Chinese egg in a batch of 50 in a London warehouse from the same shipment as that used in the Edinburgh bakery (B. C. Hobbs, personal communication). This shipment was also associated with the Surrey outbreak (Brit. med. F., 1963).

Initial inquiries at the bakery revealed that a 15-year-old apprentice "cream-worker" was ill at home with "gastric 'flu." Subsequent bacteriological investigation confirmed him as a case of paratyphoid fever. Although his illness began on 7 January he had returned to work for one day on 10 January. Bacteriological examination of blood and stool specimens from the 234 employees of the bakery was undertaken. Immediate priority was given to those employees who had been off sick since mid-December and to workers handling cream products. The staff in the many retail shops and restaurants associated with bakery $\mathrm{X}$ were also examined. As a result 15 were discovered to be infected with Salm. paratyphi B, phage type Taunton, three being symptomless. Nine general bakers (including five apprentices), two confectionery bakers, and one storekeeper were involved, as well as three retail-shop assistants. Investigations were later extended to 12 other large bakery firms, none of which uses Chinese egg ; one asymptomatic excreter was discovered. In all, 1,348 faecal and 326 blood specimens were examined.

At the same time preventive measures were put into force in the bakery. All Chinese and other eggs in bulk were pasteurized before use. A stricter regimen of personal hygiene was introduced. Central hand-washing points were set up where each worker on entry into the bakery had to scrub his hands under supervision and thereafter dip them in a quaternary ammonium solution (" roccal"). Strict attention was paid to 
the cleansing and sterilization of equipment, and toilets were continuously disinfected by a specially engaged cleaner. The standards of hygiene in the other bakeries were also checked and a printed slip in the pay-packet of all bakery employees in the city stressed the importance of personal hygiene and the need to report all bowel and influenza-like illnesses.

Meanwhile further cases, widely distributed throughout the area, continued to appear ; most of the patients had recently eaten goods containing artificial cream from bakery $\mathrm{X}$. In most clinical cases $(55 \%)$ the patients became unwell in the first four weeks of the outbreak (see Chart), before stricter hygienic measures could be instituted in the bakery.

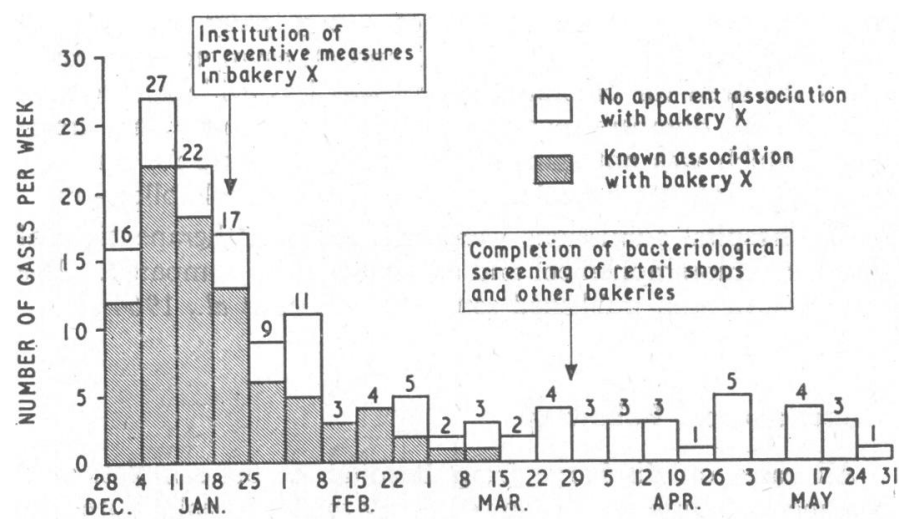

Date of onset of symptoms in the clinical cases, in weekly graphs.

The mode of discovery of all cases involved is shown in Table I. Sixty were discovered by family doctors, while 43 primary and seven secondary infections were diagnosed initially in hospitals. Routine investigation of contacts revealed a further 46 cases.

Thirty-two $(17 \%)$ cases were diagnosed clinically as enteric fever prior to bacteriological confirmation in hospital ; $19(10 \%)$ were diagnosed by blood culture, $18(9.5 \%)$ by a Widal agglutination reaction, and $91(48 \%)$ by stool culture. The remaining $28(15 \%)$ cases were diagnosed by a combination of these. Salm. paratyphi $B$ was later isolated from 14 of the 18 cases diagnosed initially on a Widal reaction.

\begin{tabular}{|c|c|c|c|c|c|c|c|}
\hline \multirow[b]{2}{*}{ Type of Case } & \multicolumn{2}{|c|}{$\begin{array}{c}\text { Investigation } \\
\text { of }\end{array}$} & \multirow[b]{2}{*}{$\begin{array}{l}\text { Family } \\
\text { Doctors }\end{array}$} & \multicolumn{2}{|c|}{ Hospitals } & \multirow{2}{*}{$\begin{array}{c}\text { Contact } \\
\text { Investi- } \\
\text { gation }\end{array}$} & \multirow[b]{2}{*}{ Total } \\
\hline & $\begin{array}{l}\text { Party } \\
\text { Children }\end{array}$ & $\begin{array}{c}\text { Bakery } \\
\text { Workers }\end{array}$ & & $\begin{array}{l}\text { Prim- } \\
\text { ary } \\
\text { Cases }\end{array}$ & $\begin{array}{c}\text { Second- } \\
\text { ary } \\
\text { Cases }\end{array}$ & & \\
\hline $\begin{array}{l}\text { Clinical } \\
\text { Asymptomatic }\end{array}$ & $\begin{array}{l}9 \\
7\end{array}$ & $\begin{array}{r}12 \\
4\end{array}$ & $\begin{array}{r}59 \\
1\end{array}$ & 43 & $\begin{array}{l}3 \\
4\end{array}$ & $\begin{array}{l}22 \\
24\end{array}$ & $\begin{array}{r}148 \\
40\end{array}$ \\
\hline Total & 16 & 16 & 60 & 43 & 7 & 46 & 188 \\
\hline
\end{tabular}

\section{Investigation of Contacts}

Those persons who had been domestic or social contacts of a case within a period of 14 days prior to onset of symptoms or since were investigated. Household contacts each submitted three stool specimens at intervals of three to four days and a sample of blood was examined serologically. Other contacts submitted at least one stool specimen. Schoolchildren and foodhandlers were kept off school or work until investigations were completed. A total of 1,432 faecal and 474 blood specimens were examined from 782 contacts, 46 of whom had evidence of paratyphoid infection.

\section{Hospital Infections}

Secondary cases arising as ward contacts occurred in two general hospitals. In two isolated instances, after the admis- sion of new patients who were later diagnosed as having paratyphoid fever, routine stool examination of contacts in each ward revealed a single symptomless excreter in a 51-year-old woman and a 10-year-old boy respectively, both of whom had been in-patients for several months. Investigation of the nursing and orderly staffs failed to reveal possible excreters.

A more serious secondary spread of infection occurred in the paediatric unit of one hospital. The index case here was of unusual interest. Baby $\mathrm{C}$, the son of the second patient in the outbreak, was transferred with his mother from a maternity ward, where he had been breast-fed, to the City Hospital at the age of 1 week. Eight days later he was discharged home after negative bacteriological reports. Three weeks later, while his mother was still in hospital, he was admitted to a surgical paediatric ward for investigation of his having little spontaneous movement in his right arm. Clinical and radiological evidence followed by the isolation of Salm. paratyphi $B$ from his stool suggested a diagnosis of salmonella osteomyelitis of the lower end of the right humerus. He was readmitted to the City Hospital, having been one week in the paediatric ward. Ten days later a baby of 4 weeks, who had shared his cubicle in the paediatric unit, developed diarrhoea and was found to have a positive stool. The paediatric-ward sister and staff nurse, both of whom had become unwell, were also admitted to the City Hospital when positive stools were reported. In addition a night nurse and another baby of 8 months were found to be symptomless execreters. Baby $C$ was finally discharged home bacteriologically negative on 16 April. In early May, however, he and his mother, who had been negative up to that time, stayed with relatives in Blackburn, West Lothian, for a week-end. Subsequently three children in this family developed paratyphoid fever and their mother became a symptomless excreter. Since then baby C and his mother have had sporadic positive stools.

\section{Household Infections}

There were 24 instances in which two or more persons residing or eating together in the same household were infected. In eight of these households there was a history of all concerned having recently consumed goods from bakery $\mathrm{X}$.

The most outstanding instance of household secondary spread was in a tenement flat from which a man aged 34 was admitted to hospital with a five-day history of pyrexia, diarrhoea, and vomiting. His two young daughters had also been unwell with some diarrhoea and pyrexia, one of them having symptoms which began about five days prior to her father's illness. The two children, the wife, and the mother of this man were all found to have positive stools. Investigation of other contacts revealed that a married brother and sister who regularly had meals with the family also had positive stools, in addition to which a sister-in-law subsequently became infected from her husband.

From another household a boy of 4 years was admitted to the City Hospital, where he was found to have a positive blood culture and Widal two months after his 5-year-old sister had returned home from hospital. Ten days later a brother of 1 year also became febrile with a positive stool and a 7 -year-old sister was found to be an asymptomatic excreter. The index case had been well since returning home and routine bacteriological follow-up was repeatedly negative.

\section{Analysis of Cases}

Of the 188 patients, $87(46 \%)$ were children under 15 years of age. More females (56\%) were affected than males (Table II). The only significant occupational factor was that 16 cases were employed as bakery workers-all except one in the bakery incriminated. In addition to five members of the nursing 
profession, five other persons were employed in food-handling occupations. Only 14 cases had a history of T.A.B. immunizations-none within the previous two years. One child had had T.A.B. within three years of his illness; his mother, with similar T.A.B. status, was a symptomless excreter. At least $106(56 \%)$ persons could have derived their infection direct from this one bakery, although 16 had a potentially double source

\begin{tabular}{|c|c|c|c|c|c|c|c|c|c|c|c|}
\hline \multirow{2}{*}{ Sex } & \multirow{2}{*}{ Type of Case } & \multicolumn{9}{|c|}{ Age in Years } & \multirow{2}{*}{ Total } \\
\hline & & -1 & $1-$ & $5-$ & $15-$ & 25- & 35- & 45- & $55-6$ & $65+$ & \\
\hline Male \{ & $\begin{array}{l}\text { Clinical } \\
\text { Asymptomatic }\end{array}$ & $\underline{2}$ & $\begin{array}{r}10 \\
1\end{array}$ & $\begin{array}{l}22 \\
10\end{array}$ & $\begin{array}{r}14 \\
1\end{array}$ & $\begin{array}{l}4 \\
1\end{array}$ & $\begin{array}{l}3 \\
3\end{array}$ & 3 & 5 & $\begin{array}{l}2 \\
1\end{array}$ & $\left.\begin{array}{l}65 \\
17\end{array}\right\} 82$ \\
\hline \multirow[t]{2}{*}{ Female \{} & $\begin{array}{l}\text { Clinical } \\
\text { Asymptomatic }\end{array}$ & $\begin{array}{l}2 \\
2\end{array}$ & $\begin{array}{r}11 \\
2\end{array}$ & $\begin{array}{r}23 \\
2\end{array}$ & $\begin{array}{r}13 \\
2\end{array}$ & $\begin{array}{l}8 \\
5\end{array}$ & $\begin{array}{l}7 \\
5\end{array}$ & $\begin{array}{l}7 \\
2\end{array}$ & $\begin{array}{l}6 \\
2\end{array}$ & $\begin{array}{l}6 \\
1\end{array}$ & $\left.\begin{array}{l}83 \\
23\end{array}\right\} 106$ \\
\hline & Total & 6 & 24 & 57 & 30 & 18 & 18 & 12 & 13 & 10 & 188 \\
\hline
\end{tabular}

of infection, having consumed goods from bakery $\mathrm{X}$ in addition to being in contact with a known case. Eighty-two had no apparent recent connexion with the bakery, and 42 of these were secondary cases (household infections). In 40 cases the exact source of infection could not be determined.

As in any outbreak, a variety of clinical presentations were observed, ranging from abortive illness to classical paratyphoid fever. Gastroenteritis was common as a presenting symptom and in some cases this proceeded to a systemic infection. In others, where one system was involved disproportionately, the exact diagnosis was temporarily obscured-for example, 14 were admitted to hospital with respiratory infections and 10 with suspected appendicitis, of whom eight had appendicectomies before paratyphoid fever was diagnosed. One case presented with osteomyelitis and two with early cholecystitis.

Of those with a clinical illness $(148$, or $79 \%$ ) the majority had classical paratyphoid fever, 74 of whom had a positive blood culture at least once and 37 had a well-marked rose-spot eruption. Forty cases ( $21 \%$ ) gave no history of recent illness, 37 being symptomless excreters at the time of discovery ; three were diagnosed on serological evidence alone. Serious complications were uncommon-haemorrhage occurred in two patients, one of whom also had a perforation. This patient was successfully treated conservatively. Acute cholecystitis occurred as a late complication in one elderly male and three female patients. Of less serious import, temporary alopecia was observed in the convalescent period in five patients (two children and three adults).

During the outbreak four persons with chronic illness died, showing evidence of paratyphoid infection, which may have been a contributory cause.

1. A man aged 58 with advanced pulmonary tuberculosis complicated by hemiplegia developed diarrhoea in hospital a few days before he died. Positive blood culture reported after death.

2. A man aged 59 with interstitial pulmonary fibrosis and advanced cardiac failure died the day after admission to hospital with a respiratory infection. Positive blood culture reported after death.

3. A woman aged 32, an old case of pulmonary tuberculosis, who had had multiple pulmonary emboli four months previously, was readmitted to hospital with a respiratory infection and died several days later. Positive blood culture.

4. A woman aged 87 with arteriosclerotic heart disease died during late convalescence after a moderately severe attack of paratyphoid fever in which respiratory symptoms dominated. Positive blood culture.

\section{Treatment and Follow-up}

One hundred and fifty-five persons were admitted to the infectious diseases unit of the Edinburgh City Hospital for treatment. Of these 139 were clinical cases and 16 were asymptomatic. Six abortive cases (with minimal symptoms but with a positive blood culture), who were discharged from hospital 8 to 10 days after admission, remained at home under close surveillance without clinical or bacteriological relapse.

The circumstances which governed the decision to treat patients at home instead of in hospital were the pressure on hospital beds at the height of the outbreak, the clinical state of the case, the suitability of the home, the wishes of the family doctor, and the absence of food-handlers, schoolchildren, or infants as household contacts. The last factor was relevant in that food-handlers and schoolchildren were cleared for return to work or school at an earlier date when the case was treated in hospital. Nine clinical and 24 asymptomatic cases were treated throughout at home, mostly with chloramphenicol or neomycin. Neomycin, in doses of $1-2 \mathrm{~g}$. daily for 10 days, was recommended for late clinical and all asymptomatic cases, when the need for chloramphenicol was less evident. Because of the small numbers involved the results of domiciliary treatment, which was not standardized, are unsuitable for analysis, but these cases are included in the bacteriological follow-up.

The hospital admissions were included in a therapeutic trial in which chloramphenicol and ampicillin were compared. The results have been published separately (Sleet et al., 1964).

\section{Bacteriological Follow-up}

All cases on discharge from hospital or on completion of treatment at home were followed up by the local health authority of the area in which they resided. Prior to discharge from hospital every patient had produced at least three consecutive negative stool and urine specimens at intervals of three to four days. With patients who were food-handlers, however, this standard was raised to six negative stools and urines. Thereafter on returning home all cases submitted six stools and one urine specimen in the first month of surveillance. Those not employed as food-handlers were allowed to return to work or school at this stage if still negative. For food-handlers and nursing staff, however, 12 negative stool specimens (and one urine) were required in the first two months before employment was resumed. Further follow-up of all cases consisted of two specimens a month for the next five months at least. Altogether $65(35 \%)$ cases produced at least one positive stool or urine.

Successful stool and urine clearance were achieved without further treatment in 23 cases, although one youth aged 18 excreted intermittently for eight weeks. Nine domiciliary cases having a bacteriological relapse became negative in due course, only two being re-treated. Seven children and one elderly man were readmitted to hospital for further treatment, after which all except baby $\mathrm{C}$ and the elderly man remained negative. Nine of 25 cases re-treated at home continued to excrete the organism. Thus three months after treatment 11 cases were still positive. Six months later four had cleared spontaneously, leaving seven faecal carriers-six females and one male, aged 16 to 77-two of whom have associated urinary carriage. Five with gall-bladder infection have been treated surgically, but were still excreting the organism two months later.

\section{Discussion}

The epidemiological role of contaminated imported food ingredients in outbreaks of paratyphoid fever is now familiar, as is the subsequent dissemination of infection by unsterilized equipment in bakeries. In this outbreak, as in many others, the vehicle appeared to be artificial cream, which was present in the products eaten by all the cases associated with bakery $\mathrm{X}$. Chinese egg was not an ingredient of the artificial cream or the custard, but was used in cake and sponge mixtures, where it was exposed to temperatures lethal to salmonellae during baking. Definite proof of the mode of transmission of the organism from the Chinese egg to the cream was not obtained, but since 
bakery $\mathrm{X}$ is an " open" bakery with internal movement of staff, as well as of equipment and products, there was ample opportunity for contamination. Contact with flour products such as pastry or cake is known to enhance the properties of artificial cream as a nutrient medium for Salm. paratyphi $B$ (Thomson, 1953 ; Brit. med. F., 1955). Another important factor is the time relation between the contamination and consumption of the infected food, especially as larger doses of Salm. paratyphi B than of Salm. typhi are required to produce clinical infection (Newell et al., 1955). In the instance of the party infections, 30 hours passed between the preparation of the trifles and their consumption.

At least 106 cases were associated with this bakery, including 15 employees and 23 party children. Further evidence incriminating the bakery was the isolation of Salm. paratyphi B, phage type Taunton, from the same shipment of egg. In addition, the organism was cultured from an untouched French cake in a box from bakery $\mathrm{X}$ in the home of one of the cases.

At least four weeks elapsed between the introduction of infection into the bakery and the institution of preventive measures as a result of the cumulative effect of the incubation period, delay in diagnosis of the early cases, and interpretation of the epidemiological background. Bakery $\mathrm{X}$ has numerous retail branches in the Edinburgh district, and many unknown persons must have been infected in these four weeks, some presumably having mild or abortive illnesses and others being symptom-free. Many such cases are likely to have achieved spontaneous stool-clearance, but others may still be excreting the organism. Those cases which had no apparent link with the bakery or known cases may have been infected from such a source or may have consumed products from bakery $\mathrm{X}$, being unaware of their origin.

Stool culture was the most common single factor in confirming the initial diagnosis (91 cases) in the outbreak and was also contributory in 23 other cases. For practical purposes it was most valuable in the very young and in the investigation of party children, but it was also of assistance in many instances as early as the first week of illness. In seven secondary cases a positive stool was obtained prior to the onset of symptoms. Serological examination, although of less general value, nevertheless confirmed the diagnosis in 18 cases where blood and stool culture failed initially.

The variable clinical picture which led to the admission of many cases to general hospitals early in the outbreak was not unexpected. An interesting aspect of the outbreak was the perinatal infection of baby $\mathrm{C}$ from his mother, the development of osteomyelitis as the presenting feature, and the secondary cases arising in the paediatric unit. The late appearance of infection in three children two months after a sibling had returned home from hospital was disturbing, when all had previously been routinely screened. Similarly a party child was negative while under close bacteriological observation in January following a mild gastro-intestinal upset, but three months later, during re-checking of all party children, she was found to have a positive stool. Such occurrences indicate the desirability of prolonged follow-up, as does the high proportion of cases $(35 \%)$ having bacteriological relapse at varying lengths of time after completion of treatment. Eleven $(5.8 \%)$ persistent excreters after three months is, however, comparable with the findings of others (Jameson, 1951 ; George et al., 1953).

In any outbreak of enteric infection many persons come under surveillance as potential cases. In this outbreak 79 suspected cases were kept under close observation before the provisional diagnosis was disproved. For several months after the incrimination of their products bakery $\mathrm{X}$ informed the Public Health Department of all employees " off sick" with gastrointestinal or febrile illnèsses, as also did other bakeries in the city for a shorter period of time. All employees thus notified were kept off work until cleared clinically and bacteriologically. Bakery X continued to pay the wages of all employees, but many other food-handlers suffered financially during the investigations. Unfortunately there are no legal provisions in Scotland for the payment of compensation to workers excluded from employment in the interests of the public health, as has been provided for England and Wales in Section 41 of the Public Health Act 1961.

Under recently introduced regulations (Statutory Instruments, 1963a, 1963b) which came into force on 1 January 1964 no liquid or frozen whole egg (except liquid egg broken on the premises), whether home-produced or imported, may be used as an ingredient of food for human consumption unless it has been pasteurized. As a result of this, along with technical advances designed to render egg albumen and desiccated coconut safe, it is to be hoped that similar outbreaks of paratyphoid fever will not occur in the future.

\section{Summary}

An outbreak of paratyphoid fever due to Salm. paratyphi $B$, phage type Taunton, infecting 188 persons in the Edinburgh area in the early months of 1963 is described. The vehicle of infection appeared to be bakery confectionery with artificial cream contaminated by imported Chinese egg. Particulars are given of the epidemiological control measures. The preventive measures taken in the bakery and with contacts of cases are detailed.

There were 106 females and 82 males infected; $46 \%$ were children under 15 years of age. Forty cases were completely symptomless and the clinical condition in the other 148 varied from abortive illnesses to classical paratyphoid fever. Stool culture confirmed the initial diagnosis in 91 cases and was contributory in 23 others. A positive blood culture was obtained in $50 \%$ of clinical cases. Serious complications were uncommon, but four persons with chronic illnesses who died showed evidence of paratyphoid infection.

Examples of secondary spread of infection in family groups and in a hospital paediatric unit are mentioned. A description is given of the bacteriological follow-up on discharge from hospital and on completion of domiciliary treatment, during which 65 cases relapsed, seven of them still being carriers.

Our thanks are due to Dr. H. E. Seiler, medical officer of health to the City of Edinburgh, to Professor R. Cruickshank, University of Edinburgh Bacteriological Department, and to Dr. J. M. Mair, senior medical officer (infectious diseases), for their helpful criticism and for permission to publish this paper. We should also like to thank all who provided details of cases, especially general practitioners, surgical and medical staffs of hospitals, and the public health departments of adjacent counties; the bacteriological laboratory staffs of the University of Edinburgh and the City Hospital for their help with the investigations and follow-up; Dr. E. S. Anderson, Central Enteric Reference Laboratory, Colindale, for the phagetyping; bakery $\mathrm{X}$ for full co-operation; and Mr. A. Orr, senior sanitary inspector (City of Edinburgh), for his very able assistance.

\section{REFERENCES}

Anderson, J. P. (1962). Newc. med. F., 27, 6.

Brit. med. Ұ., 1955, 2, 1315 .

Brit. med. $1963,1,1175$.

Cameron, A. D. C. S. (1959). Med. Offr, 102, 330.

Cockburn, W. C., Jameson, J. E., and Fenton, J. (1951). Mth. Bull. Minist. Hlth Lab. Serv., 10, 43.

George, T. C. R., Harvey, R. W. S., and Thomson, S. (1953). F. Hyg. (Camb.), 51, 532 .

Jameson, J. E. (1951). Mth. Bull. Minist. Hlth Lab. Serv., $10,49$.

Macgregor, A. S. M. (1940). A.R. med. Offr Hlth, City of Glasgow, 3, 26.

26. B. (1948). Mth. Bull. Minist. Hlth Lab. Serv., 7, 241.

Moore, B. (1948), Mth. Bull. Minist. Hlth Lab. K. G. W. (1955). Brit. med. f., 2, 1296.

Sleet, R. A., Sangster, G., and Murdoch, J. McC. (1964). Ibid., 1, 148. Statutory Instruments (1963a). No. 1503. The Liquid Egg (Pasteurization) Regulations, 1963 .

(1963b). No. 1591. The Liquid Egg (Pasteurization) (Scotland) Regulations, 1963.

Thomson, S. (1953). Mth. Bull. Minist. Hlth Lab. Serv., 12, 187.

Young, W. C. (1960). Hlth Bull., 18, 1, 14. 